\title{
Potentials of ground penetrating radar for the assessment of outer stone masonry leaves
}

\author{
Charles Bridge in Prague \\ Jan Válek, Jakub Havlín, Monika Slavíková
}

\begin{abstract}
Ground penetrating radar equipped with $2 \mathrm{GHz}$ high frequency bi-polar antenna was experimentally used as one of the methods for the assessment of outer stone masonry leaf of the Charles Bridge $\left(14^{\text {th }}\right.$ century) in Prague. The applicability of the method was first studied on previously extracted masonry blocks. This allowed a more detailed study of expected defects and of various material inhomogeneities including grouting materials that were to be expected during the assessment of the real structure. These model situations were useful for determination of an optimal radar set up and also its resolution and clarification of potentials for detection of expected defects like voids, irregular detached surfaces, elevated moisture content and reflection of signal from the irregular rear plane of a stone block. It also uncovered important influences of several types of sandstones used in the structure. There have been more than seven different types of sandstone identified in the structure. The final step was a trial assessment of the masonry in situ. After the evaluation, the GPR method was recommended for the assessment of the facing stone units of the bridge.
\end{abstract}

Keywords-GPR, ground penetrating radar, masonry assessment

\section{Introduction}

The construction of the Charles Bridge in Prague begun in 1357 and it replaced an older bridge (Judith Bridge) which was severely damaged by a flood in 1342 . It takes its name after the king Charles IV who ordered its construction and who largely initiated and supported the development of mediaeval Prague and the Czech kingdom of that time. Nowadays, it is a prominent structure of a great cultural heritage significance in Europe and it is protected as a national monument. Throughout the history, it was several times badly damaged by floods and the structure was consequently several times reconstructed.

\section{Jan Válek}

Institute of Theoretical and Applied Mechanics, Academy of Sciences The Czech Republic

\section{Jakub Havlín}

Faculty of Restoration, University of Pardubice

The Czech Republic

\section{Monika Slavíková}

Faculty of Restoration, University of Pardubice

The Czech Republic

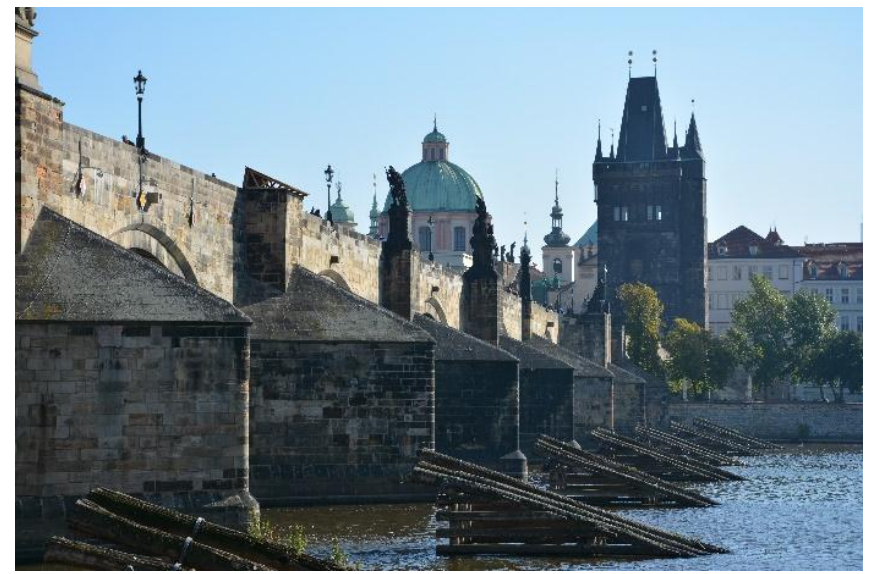

Figure 1. The south side of the Charles Bridge in Prague

Apart of that, other major structural interventions were carried out including strengthening of foundations of the piers in 18th and 19th century and in the 70th of the 20th century a reinforced concrete slab was cast above the vaults to tie the side walls and to stop ingress of water through the pavement layers.

The Charles Bridge itself is $621 \mathrm{~m}$ long and about $10 \mathrm{~m}$ wide with 16 archers crossing the river Vltava. The structure is a typically medieval stone masonry with massive piers and vaults. The outer masonry is made of sandstone blocks bonded with the rest of inner solid masonry made of a rubble units and lime mortar [1]. The stone masonry have been exposed to relatively harsh weathering conditions for a long time and deterioration occurred mainly due to elevated moisture content in combination with freeze-thaw cycling and due to presence of salts and their crystallization pressure. The sandstone masonry of the piers is additionally exposed to an elevated moisture content and forces caused by the current of the river at the water level and below.

Therefore, at present, any repair and restoration work is facing complex material and structural problems. One of the issues is a stone repair and replacement of the outer masonry leaf which was commonly already repaired and partially rebuilt for several times in the past.

\section{Aims and Methods}

The outer masonry face appears as built of regularly cut sandstone blocks of different sizes and origin. Locally, there is possible to identify earlier stone replacements by the type of sandstone or by irregularities in joints.

However, to understand the outer leaf structure, there is a need to know the depth of facing stones and their bonding with the whole masonry wall. For this purpose, the use of GPR was suggested. The aim of the study was thus an evaluation of the use of a high frequency GPR for the 
assessment of the outer masonry leaf structure. It focused on the thickness of stone unites and their bond with rest of masonry.

The high frequency ground penetrating radar method was proposed for the assessment as it is a non-destructive method which can assess larger areas with a good precision and in a relatively good time. An impact echo method was also considered and tested [2] however this paper focuses solely on the use of GPR as it was finally recommended as the main method of the assessment [3].

The equipment - GPR from Italian company IDS with 2 $\mathrm{GHz}$ bipolar antenna and Aladin system was used for the assessment. Signal velocity was set to $140 \mathrm{~mm} / \mathrm{ns}$. Wheel resolution was $0.4 \mathrm{~mm}$ and reading was taken at 1024 samples per scan. The principles of operation of GPR and its application to masonry can be found elsewhere $[4,5,6]$. The obtained data were processed in the Slice software. Binda et al. [7] describes a morphology of masonry of historic structures and its diagnostics.

\section{Preliminary Study on Removed Masonry Blocks}

Initially, larger stone masonry blocks which were withdrawn from the bridge during previous repairs were assessed to evaluate the method with a possibility to examine also the inner structure that was partially visible. An example from this initial measurement is given for a stone block No. 133 composed of original Žehrovice sandstone and two replacement stones (Božanov sandstone) cemented with an adhesive mortar, see the drawing on Figure 2. The radargrams are presented on Figure 3. The thickness of the first stone slab is clearly visible and identifiable by the reflected signal from the interface sandstone božanov - cement grouting. However, the next interface grouting - sandstone (Žehrovice) was not identifiable. The last reflection is from the end of the block. However, the cement based grouting attenuated the signal differently along the scan.

Another example is a block No. 82VA. In this case a decayed part of the original block (Hořice sandstone) was replaced by a new piece of Libná sandstone, see figure 4 . The radargram on figure 5 shows reflection at the end of the Hořice sandstone block. However, both Libná sandstone and the cement based grouting caused attenuation of the signal. The interface between the Libná sandstone and the grouting is possible to determine but the reflection is relatively weak. Moreover, there is a reflection artefact on the right hand side which is not accompanied by hyperbolic reflections.

This initial study allowed to understand the expected inner structure and behaviour of different types of sandstone and other materials. It proved that the GPR can be used to determine the thickness of stone units. The assessment of the inner structure depends on the type of sandstone and the presence of cement grouting as it can attenuate the signal. The precision of the measurement decreases with the depth of the interface reflection. For the depth of $150 \mathrm{~mm}$ the error is about $2-3 \%$, for the depth around $400 \mathrm{~mm}$ the error is about $10 \%$. Altogether 9 different composed sandstone blocks were assessed.

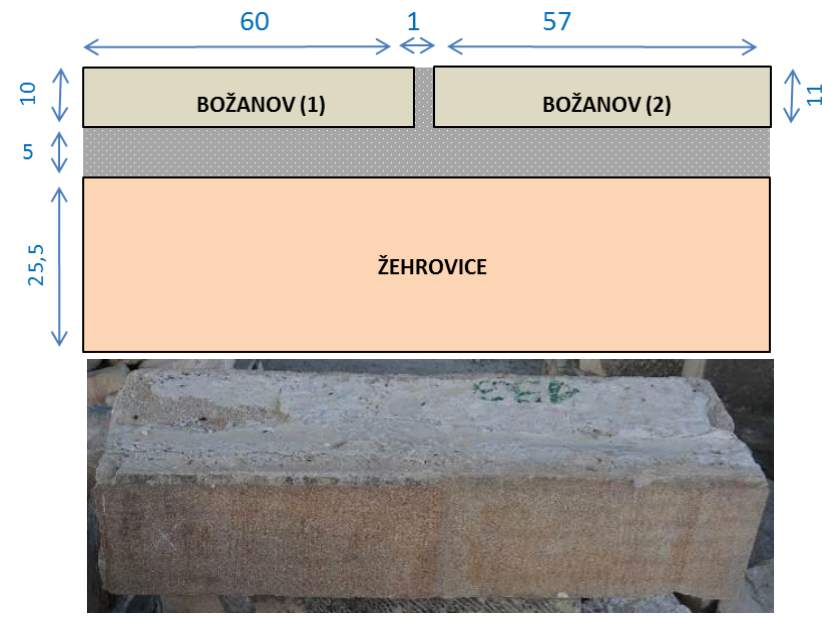

Figure 2. Dimensions and photo of the assessed block No. 133

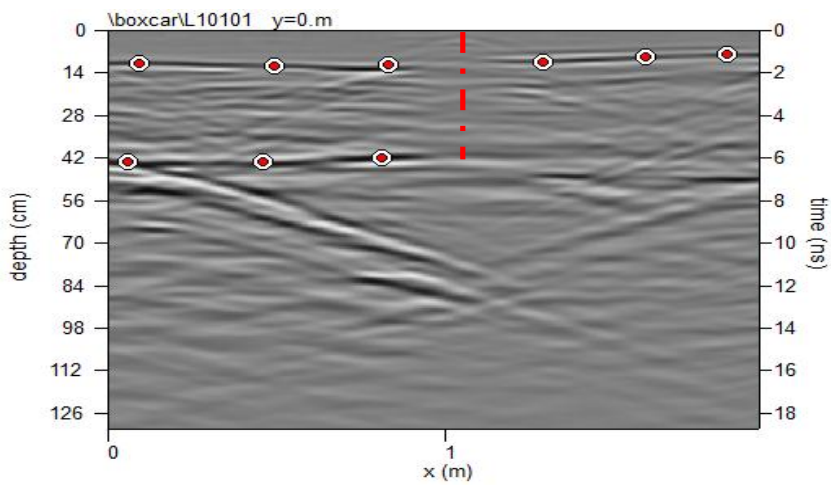

Figure 3. A radargram taken in the middle of the block. The dots mark points at which the depth was determined to calculate precision of such reading. The first layer - facing stone, the second layer - end of block.

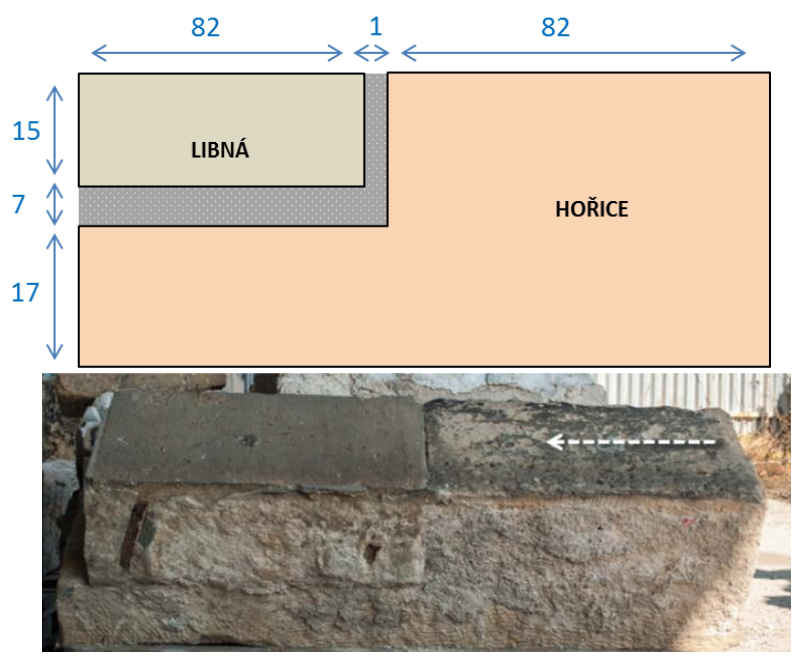

Figure 4. Dimensions and photo of the assessed block No. 82VA. The white arrow is the direction of scan taken.

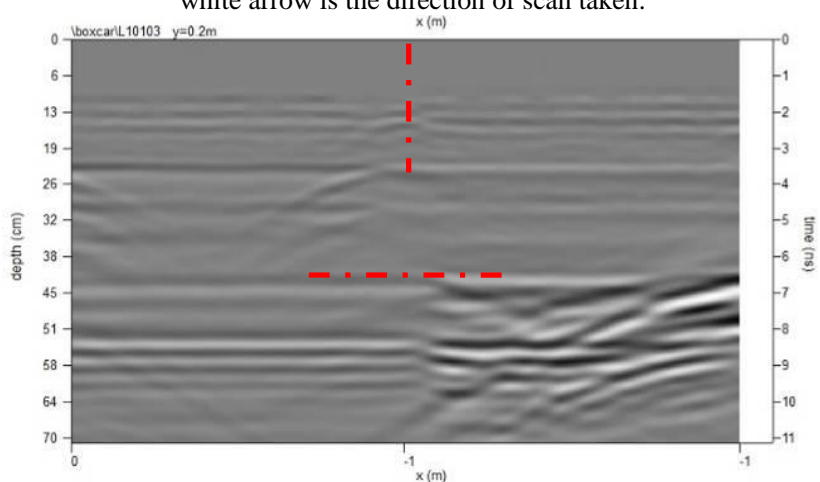

Figure 5. A radargram taken in the middle of the block $82 \mathrm{VA}$. 


\section{Iv. Assessment of Masonry In Situ}

Trial assessment of masonry of the bridge was carried out in situ on a pier shown on Fig. 6. The initial setting was kept the same as for the previous measurements on the blocks. The whole area was assessed by horizontal scans taken in longitudinal direction $5 \mathrm{~cm}$ apart. Only typical scans are presented below to demonstrate the measurement outputs. There were 5 other similar sized areas assessed in situ on the bridge.

From the preliminary study, it was known that the GPR with $2 \mathrm{GHz}$ antenna is able to determine the thickness of stone units, i.e. of the first interface between the facing stone and mortar or voids. The second consequent interface, i.e. mortar - stone interface, is possible to determine only for some types of sandstone and grouting. In the case of the assessment of the Charles Bridge, the main task was to develop a methodological guidelines for the assessment of the outer masonry leaf with a special attention to the thickness of the replaced facing stones. This was due to a fact that a higher number of such replacements and their loose connection to the structure could affect the structural behaviour and stability of the masonry leaf. Therefore, such "thin" facing stones are going to be especially considered in a further study dealing with structural consolidation of masonry.

In order to interpret the obtained GPR scans, three main categories were distinguished: (1) stone - whole block of original or replaced stone (at least seven different types); (2) well connected facing stone - replacement of a facing part (10-30 cm thickness) with grouting and (3) loosely connected facing stone - replacement of a facing part with a void behind or incompletely grouted.

A typical scan for the masonry layer marked $\mathrm{A}$ is presented on Fig. 7. In this case the GPR assessment identified well the thickness of the stone units. The depth of the reflection from the end of stone interface is about 15-20 $\mathrm{cm}$ and it suggests that these stone units are only facing stones that replaced the larger (deeper) historic ones. All of them are probably well connected with the masonry behind and there is no reflection that would suggest the ends of original stone blocks. This is probably due to the attenuation of the grouting mortar behind the blocks. Potentially less well bonded are stone units marked as A3, 4 and 5 . However, there is no larger void producing a repetitive reflection of the signal. The corner stone A8 does not have a rectangle shape and its rear side is widening towards the corner. The shape of the reflection corresponds to the rear side. This means that units A6 and 7 are relatively regularly cut blocks as opposite to e.g. unit A1 and A4 with rather rough rear surface.

The GPR assessment of masonry layer B is presented on Fig. 8. Similarly to the layer above (A) there are reflections at the depth of $15-20 \mathrm{~cm}$ which is attributed to newer facing stones. Original stone depth is assumed to be around $30 \mathrm{~cm}$ (B4 and B8) with occasional larger bonding stones. Stone unite B1 caused exceptionally high attenuation of the signal. Deeper reflections are not forming any clear pattern to allow interpretation regarding the structural morphology of the masonry.

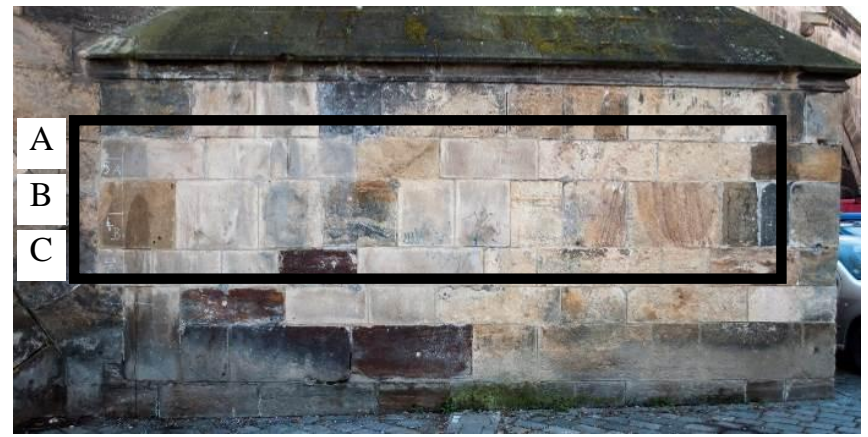

Figure 6. Trial assessment carried out in situ on three layers of sandstone masonry marked by the square.

They could be associated with a certain inhomogeneities of masonry like larger stone blocks (B2, 3, 8 have reflections around $60-75 \mathrm{~cm}$ ) or possibly also metallic objects (B11 - hyperbolic reflection). Irregular reflections behind the blocks B4, 7 and 8 suggests rubble stone masonry. The reflections near the corner can be interpreted as irregular inhomogeneous rubble masonry.

A typical scan representing the assessment of the layer $\mathrm{C}$ is presented on Fig. 9. The reflections at the depth of 15-20 $\mathrm{cm}$ are attributed to the replaced facing stones. Unit $\mathrm{C} 4$ is probably one of the remaining older blocks that reaches the depth of $60 \mathrm{~cm}$. Reflection at this depth is also noted for stone unite $\mathrm{C} 9$. The hyperbolic reflections behind the block C5 can be interpreted as several stone units (perhaps the joints of the historic masonry blocks) or possibly also metallic objects.

\section{v. Conclusions}

The presented study demonstrate the possibility to use GPR for the assessment of a thickness of sandstone blocks built in a masonry wall. The advantage is that the technique is fully non-destructive and can be used on historic masonry fabric. The assessment determined several limits for its practical use, the main one is that some types of sandstone and cement based grouting cause attenuation of signal and significantly limits the assessment of deeper masonry structure. Therefore, the GPR was proposed as a method mainly for determination of the outer masonry leaf and the depth of the facing stones. The accuracy of the determined depth depends on dielectric properties of material that are consequently influenced by the presence of moisture in the pore system. From the assessment of stone blocks of known thickness and moisture content (3-4 \% wt.-) the average propagation speed was set to $140 \mathrm{~mm} / \mathrm{ns}$. Based on this an error caused by the variability of measurement was calculated. The thickness of facing stone slabs around 100 $150 \mathrm{~mm}$ can be determined with accuracy $\pm 10 \mathrm{~mm}$ for this measuring set up ( $2 \mathrm{GHz}$ antenna), providing the sandstone has around average moisture content corresponding to the outdoor weather conditions.

Based on the preliminary measurements a methodological procedure was written for the assessment of such type of masonry outer leaf structure. This procedure was accepted by the national Cultural Heritage Protection Institute as suitable for documentation of the state of masonry morphology. This methodology thus can play an important role in the assessment prior the structural evaluation and design of any conservation procedures. 
Proc. of the Third Intl. Conf. on Advances in Civil, Structural and Construction Engineering - CSCE 2015

Copyright $(\odot$ Institute of Research Engineers and Doctors, USA .All rights reserved.

ISBN: 978-1-63248-079-8 doi: 10.15224/ 978-1-63248-079-8-60

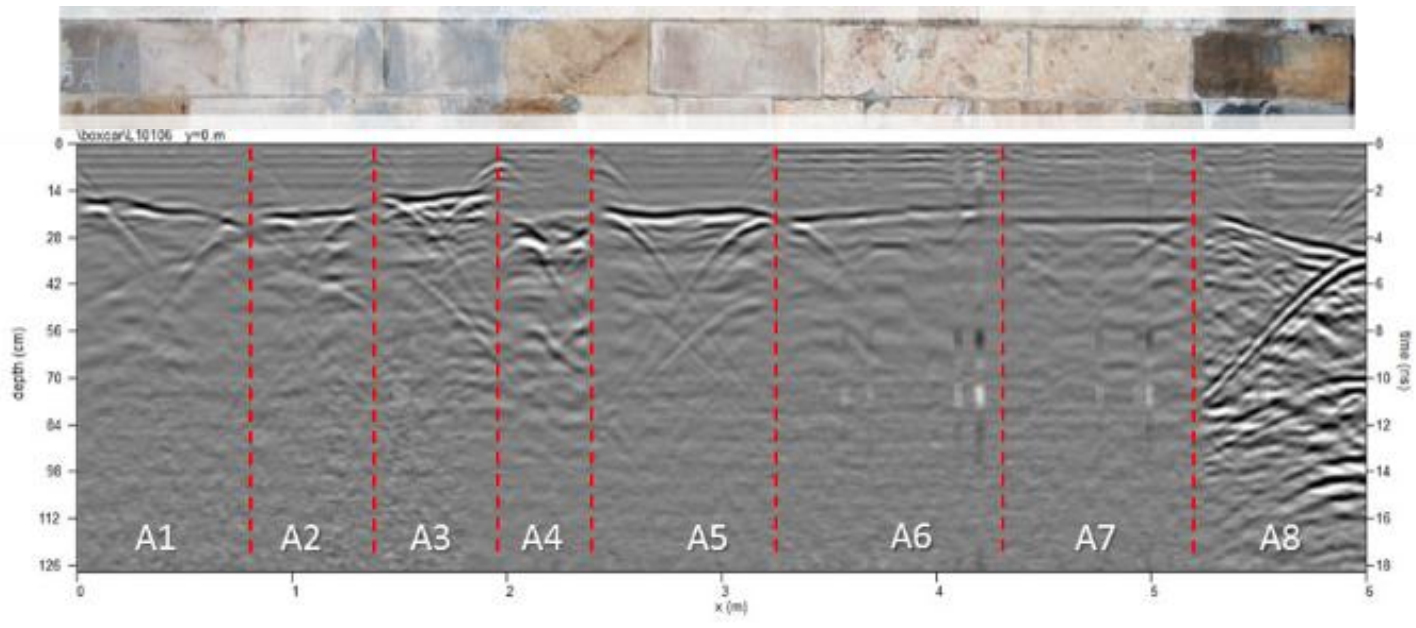

\begin{tabular}{|c|c|c|c|c|c|c|c|c|}
\hline & \multicolumn{9}{|c|}{ facing stone } & \multicolumn{2}{c|}{ stone } \\
\hline Depth [cm] & $15-17$ & $19-18$ & $13-14$ & 22 & $17-18$ & $18-19$ & 20 & $20-30$ \\
\hline
\end{tabular}

Figure 7. A representative GPR scan of the masonry layer A.

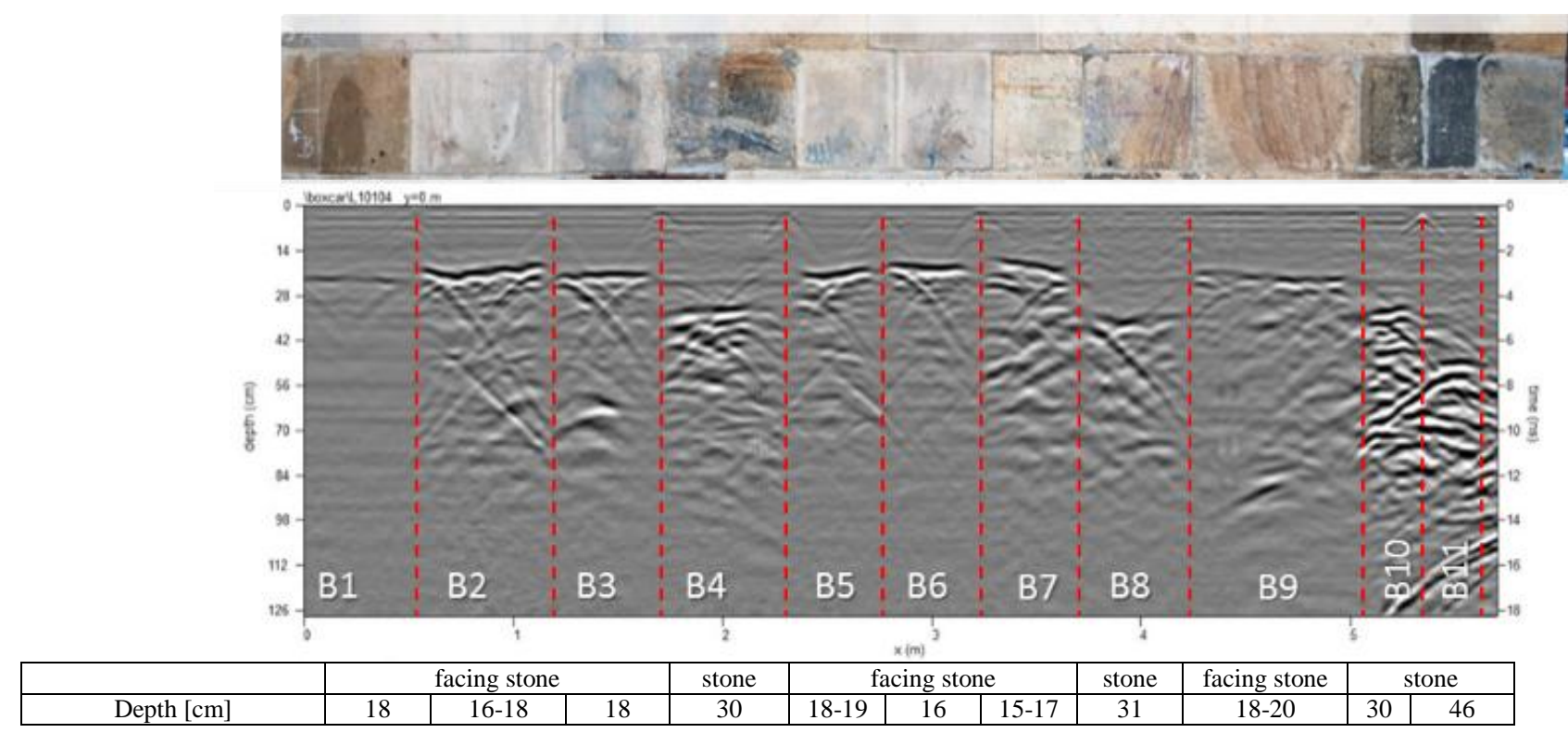

Figure 8. A representative GPR scan of the masonry layer B.

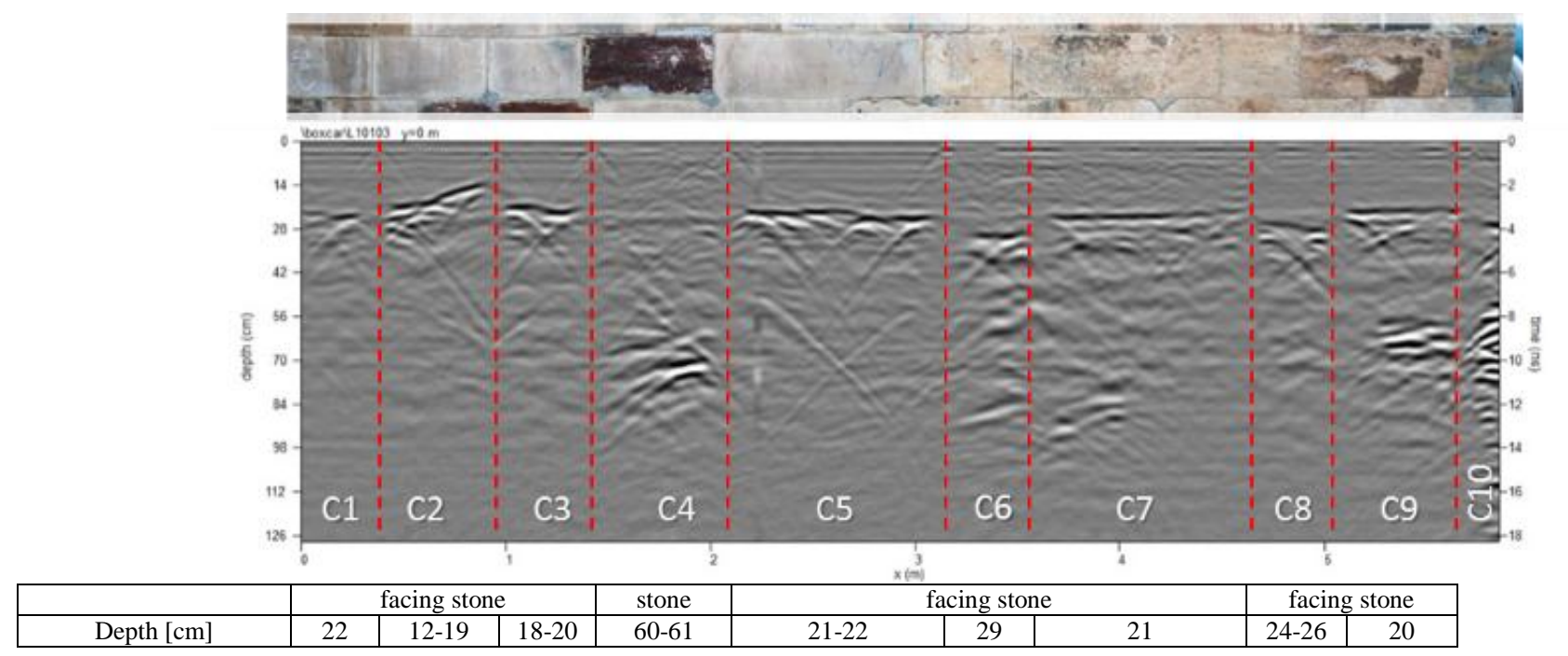

Figure 9. A representative GPR scan of the masonry layer C. 


\section{Acknowledgment}

This study is an output of a project "Selected procedures for conservation of sculptural and architectural monuments" DF11P01OVV027 supported by the Ministry of Culture of the Czech Republic within the NAKI funding scheme.

\section{References}

[1] R. Přikryl, Z. Weishauptová, M. Novotná, J. Přikrylová and A. Št’astná, "Physical and mechanical properties of the repaired sandstone ashlars in the facing masonry of the Charles Bridge in Prague (Czech Republic) and an analytical study for the causes of its rapid decay", in Environ. Earth Sci. 63, 2011, pp. 123-1639.

[2] J. Havlín, M. Slavíková and J. Válek, "Possibilities of non-invasive assessment of sandstone ashlar structures at the Charles Bridge", in Stavební obzor, vol. 9-10, 2014, pp. 151-160.

[3] J. Havlín, M. Slavíková, P. Gláser, K. Pavelka and J. Válek, "Assessment of outer sandstone masonry leaf of historic structures by the GPR non-invasive analytical technique", unpublished methodological guidelines

[4] D. Goodman, Y. Nishimura and J.D. Rogers, "GPR time slices in archaeological prospection", in Archaeological Prospection, vol. 2, issue 2, 1995, pp. 85-89.

[5] European Commission, "On-site investigation techniques for the structural evaluation of historic masonry buildings", Onsiteformasonry - EC report, Luxumberg 2006.

[6] M. J. Harry, "Ground penetrating radar theory and applications" Elsevier, 2009.

[7] L. Binda, A. Saisi and C. Tiraboschi, "Investigation procedures for the diagnosis of historic masonries", in Construction and Building Materials, vol. 14, n. 4, 2000, pp. 199-233.

About Authors: Dr. Válek is an engineer architect working in the field of diagnostics of historic structures and materials. Dr. Havlín and Dr. Slavíková are chemists working at University of Chemistry and technology and cooperate with the Faculty of Restoration as scientists on conservation projects.

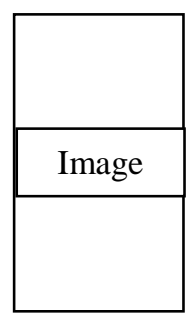

[These model situations were useful for determination of an optimal radar set up and also its resolution and clarification of potentials for detection of expected defects like voids, irregular detached surfaces and reflection of signal.] 